\title{
ANATOMO-PATHOLOGICAL EVALUATION OF ANIMALS RESCUED FROM A PETROLEUM ENVIRONMENTAL ACCIDENT *
}

\author{
SOUSA, R.S. ${ }^{1}$; LANGE, R.R. ${ }^{1}$; WERNER, J. ${ }^{2}$; JAVOROUSKI, M.L. ${ }^{2,3}$ \\ ${ }^{1}$ Departamento de Medicina Veterinária, UFPR; \\ ${ }^{2}$ Curso de Pós-Graduação em Ciências Veterinárias, UFPR; \\ ${ }^{3}$ Médico Veterinário, Zoológico de Curitiba.
}

On July 16, 2000, happened in Araucaria, a city near to Curitiba, Paraná State, Southern Brazil, an oil accident by the leaking of about 4 million liters of cusiana oil (containing aromatic hydrocarbons and heavy metals), into Barigüi and Iguaçu rivers. As might easily can be concluded, this environmental accident resulted in a great impact to the local fauna and flora. An emergencial rescue program was instituted. The rescued animals, all of them covered by a great layer of oil, were sent to Curitiba's Zoo. An attendance structure was set up and all of the rescued animals, alive or dead, were identified and registered. They received a control number and they were submitted to a standard process to remove the oil. The gross and histopathology analyses were conducted by the Veterinary Pathology Service (UFPR). A total of 203 animals were necropsied, including several species of birds, fishes, mammals, reptiles and amphibians. The dead rescued animals (165) had severe autolitic changes,turning the gross and microscopic analyses difficult. In the birds, gross changes were found in the liver: discoloration (yellow or orange) with lack of consistence; pasty or granular black substances in the digestive system and in some parasites (nematoids) were seen in some birds; eventually submeningeal hematomas were observed. The microscopic exam of the liver revealed fatty degeneration. Dietary, hypoxic and toxic factors can cause degenerative changes in the liver. Most of the animals rescued alive and dead were covered with oil. This fact probably turned the feeding difficult and made possible the development of hepatic lesions. In the same way, many necropsied animals had pasty black material covering the internal surface of the esophagus, proventriculus, gizzard, associated with macro and microscopic changes compatible with liver fatty degeneration in different degrees. In several species oil poisoning can cause this lesion. The granular black material that covered the internal surface of the proventriculus and gizzard in some birds, might have been the powdered activated coal that was supplied to the animals as part of the standard process to remove the oil. The parasites in the abdominal cavity and/or in the digestive system were expected to be found in wild life animals. The submeningeal hematoma found in three animals was indicative of traumatic lesion. The reptiles grossly examined (a freshwater turtle and two snakes) also displayed a black pasty material in the digestive and respiratory systems. The mechanism of the lesions due to oil poisoning include direct irritation to the mucous membranes, skin and respiratory system and aspiration pneumonia. The gross lesions found in this case were related to the digestive system (presence of oily material), respiratory system (pneumonia) and hepatic and renal degeneration. Although most of the necropsied animals did not exhibit changes that allow an etiologic diagnosis, the fatty degeneration observed macro and microscopically, in this case, coud be associated with a carbohydrate defficit, as well as, it could had been caused by the ingestion or absorption of the oil that covered the skin, feathers and the internal surface of the digestive system. Macro and microscopic changes in mucous membranes and skin were not observed in this case. 
Key Words: oil pollution, wild life, anatomo-pathology. Research financed by PETROBRAS. 